УДК 547.918:547.859:543.51:661.167.7:581.142

\title{
МОЛЕКУЛЯРНЫЕ КОМПЛЕКСЫ САПОНИНОВ ПЛЮЩА И СОЛОДКИ С ЦИТРАТОМ СИЛДЕНАФИЛА (ВИАГРОЙ) И ИХ БИОЛОГИЧЕСКАЯ АКТИВНОСТЬ
}

\author{
(ㄱ) Л.А. Яковишин ${ }^{1 *}$, А.В. Лекарь ${ }^{2}$, Е.В. Ветрова ${ }^{2}$, Н.И. Борисенко ${ }^{3}$, С.Н. Борисенко ${ }^{2}$, В.И. Гришковец ${ }^{4}$ \\ ${ }^{1}$ Севастопольский национальный технический университет, \\ ул. Университетская, 33, Севастополь, 99053 (Украина), \\ e-mail: chemsevntu@rambler.ru \\ ${ }^{2}$ НИИ фризической и органической химии Южного фредерального, \\ университета, пр. Стачки 194/2, Ростов-на-Дону, 344090 (Россия)

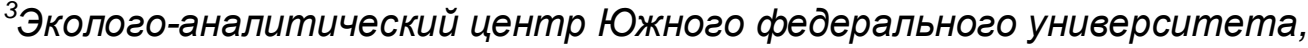 \\ ул. Зорге 7, Ростов-на-Дону, 344090 (Россия) \\ ${ }^{4}$ Таврический национальный университет им. В.И. Вернадского, \\ пр. Вернадского, 4, Симфрерополь, 95007 (Украина)
}

\begin{abstract}
Впервые методом масс-спектроскопии с ионизацией электрораспылением исследовано молекулярное комплексообразование тритерпеновых гликозидов $\alpha$-хедерина (3-O- $\alpha-L$-рамнопиранозил- $(1 \rightarrow 2)-O-\alpha-L$-арабинопиранозида хедерагенина), хедерасапонина $\mathrm{C}(3-O-\alpha-L$-рамнопиранозил- $(1 \rightarrow 2)-O-\alpha-L$-арабинопиранозил-28-O- $\alpha-L$-рамнопиранозил- $(1 \rightarrow 4)-O-\beta-D$-глюкопиранозил- $(1 \rightarrow 6)-O-\beta-D$-глюкопиранозида хедерагенина) и глицирама (моноаммонийной соли глицирризинового кислоты) с цитратом силденафила. Гликозиды образуют комплексы состава $1: 1$. Изучено влияние комплексов на всхожесть семян Avena sativa и их ихтиотоксичность против Poecilia reticulata.

Ключевые слова: тритерпеновые гликозиды, $\alpha$-хедерин, хедерасапонин С, глицирам, цитрат силденафила, молекулярный комплекс, масс-спектроскопия, ихтиотоксичность, аллелопатическая активность.

Работа выполнена при частичной финансовой поддержке грантов РФФИ 11-03-12141-офи-м-2011, Президента РФ МК-4425.2011 и гранта Минобрнауки РФ ДПННиТ №: 3.5193.2011.
\end{abstract}

\section{Введение}

Молекулярное капсулирование лекарственных веществ растительными сапонинами является перспек-

Яковишин Леонид Александрович - доцент кафедры физики, кандидат химических наук,

тел.: (3-0692) 43-51-06, e-mail: chemsevntu@ rambler.ru Лекарь Анна Владимировна - младший научный сотрудник, тел.: (7-863) 297-52-07,

e-mail: boni@ipoc.rsu.ru

Ветрова Елена Владимировна - старший научный сотрудник, кандидат биологических наук, тел.: (7-863) 2-43-47-00, e-mail: bell@ ipoc.rsu.ru Борисенко Николай Иванович - директор, кандидат химических наук, доцент, тел.: (7-863) 297-52-07, e-mail: boni@ipoc.rsu.ru

Борисенко Сергей Николаевич - научный сотрудник, кандидат химических наук, тел.: (7-8-918) 536-37-08, e-mail: sborisen@ipoc.rs.ru

Гришковец Владимир Иванович - заведующий кафедрой физической и аналитической химии, доктор химических наук, профессор, тел.: (3-0652) 608-497, e-mail: vladgri@ukr.net тивным направлением по созданию новых низкодозных препаратов. Гликозидное клатрирование можно использовать для улучшения растворимости, повышения биодоступности и расширения спектра биологической активности различных фармаконов [1]. Наиболее подробно исследованы молекулярные комплексы глицирризиновой кислоты (GA), преобладающего тритерпенового сапонина солодок и ее моноаммонийной соли (глицирама, GC) [1-5]. Начато изучение молекулярных комплексов главных тритерпеновых гликозидов плющей $\alpha$-хедерина (3-O- $\alpha-L$-рамнопиранозил- $(1 \rightarrow 2)-O-\alpha$ $L$-арабинопиранозид хедерагенина, гликозид 1) и хедерасапонина С (3-O- $\alpha-L$-рамнопиранозил- $(1 \rightarrow 2)-O-\alpha-L-$ арабинопиранозил-28- $O-\alpha-L$-рамнопиранозил-( $1 \rightarrow 4)-O$ $\beta$ - $D$-глюкопиранозил- $(1 \rightarrow 6)-O-\beta-D$-глюкопиранозид хедерагенина, гликозид 2) [6].

\footnotetext{
* Автор, с которым следует вести переписку.
} 


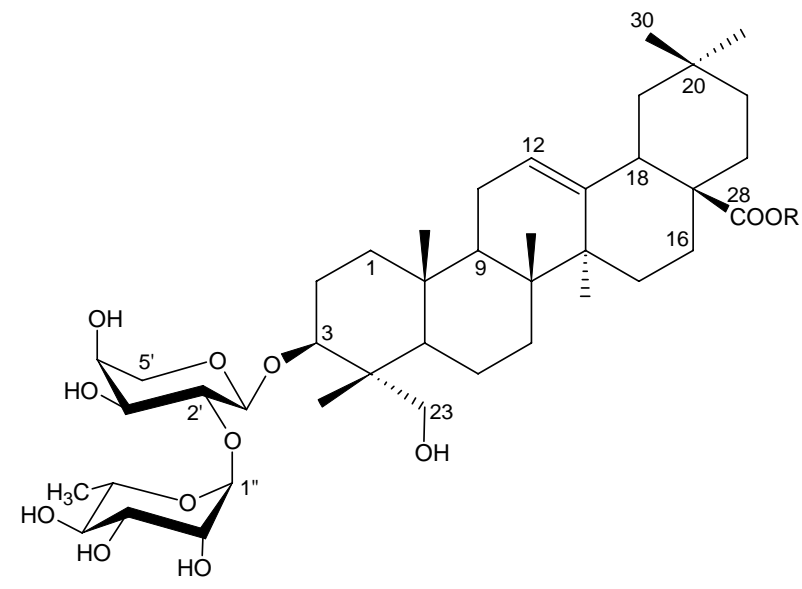

Гликозид 1: $\mathrm{R}=\mathrm{H}$

Гликозид 2: $\mathrm{R}=\leftarrow \beta \mathrm{Glc}_{p}-(6 \leftarrow 1)-\beta \mathrm{Glc}_{p}-(4 \leftarrow 1)-\alpha \mathrm{Rha}_{p}$<smiles>CCCc1nn(C)c2c(=O)[nH]c(-c3cc(S(=O)(=O)N4CCN(C)CC4)ccc3OCC)nc12</smiles>

SC

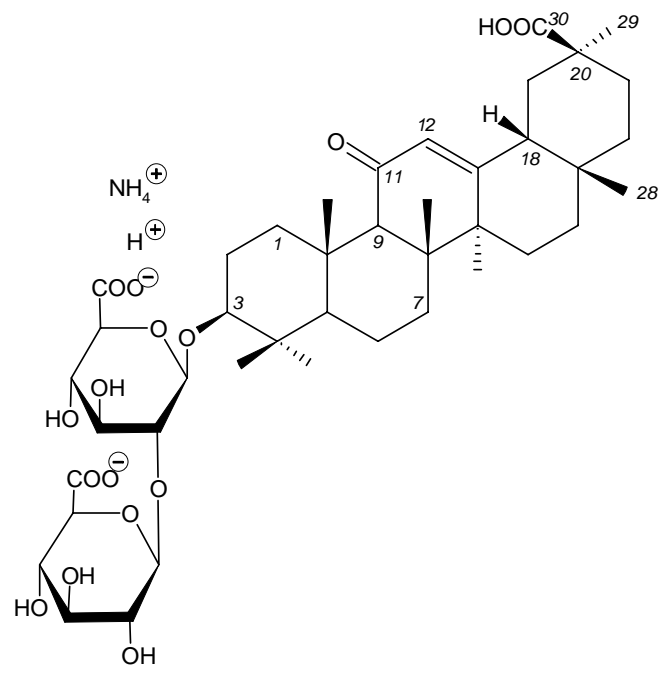

GC

Недавно были получены и УФ- и ИКспектроскопически охарактеризованы комплексы GC и гликозидов 1 и 2 с цитратом силденафила (SC) $[7,8]$. Силденафил (Sil) в виде цитрата является действующим веществом лекарственного препарата виагра, который применяется для лечения эректильной дисфункции [9]. Рассмотрено влияние комплексов гликозидов 1 и $\mathbf{2}$ с SC на электрическую активность нейронов моллюска Helix albescens [10] и всхожесть семян овса посевного Avena sativa L. [8]. Литературные данные о масс-спектрометрическом исследовании смесей тритерпеновых гликозидов с

SC отсутствуют. Поэтому в настоящей статье рассмотрено комплексообразование GC и гликозидов 1 и 2 методом масс-спектрометрии с ионизацией электрораспылением. Для систематизации сведений по биологической активности комплексов изучены их тиотоксическая и аллопатическая активности.

\section{Экспериментальная часть}

Гликозиды 1 и 2 выделяли из листьев плющей крымского Hedera taurica Carr. и канарского Hedera canariensis Willd. (Araliaceae Juss.) и подтверждали их строение как описано в работах [11, 12]. Использовали образцы SC фирмы «Shilpa Medicare Limited» (Индия) и GC фирмы «Calbiochem» (США). Комплексы гликозидов 1 и 2 с SC препаративно получали путем смешивания по 0,1 ммоль веществ с 25 мл смеси 70\% водного раствора этанола и хлороформа, взятых в соотношении $3: 1$ по объему. Комплекс GC и SC получали смешиванием по 0,1 ммоль веществ с 25 мл 70\% водного раствора этанола. Полученные смеси выдерживали при 40-50 ${ }^{\circ} \mathrm{C}$ в течение 1,5 ч при постоянном перемешивании. Растворители отгоняли в вакууме.

Масс-спектры получены на спектрометре Bruker Daltonics micrOTOF-Q с прямым вводом пробы, ионизация электроспреем, детектирование отрицательных и положительных ионов в интервале от 50 до 3000 Да с точностью не менее $1 \times 10^{-2}$ Да. Напряжение на капилляре распылителя $\pm 4200 \mathrm{~B}$, параметры газаосушителя (азот «осч», 5 л/мин, $\left.180{ }^{\circ} \mathrm{C}\right)$ и энергия ионов на квадруполе $(5,0$ эВ) оптимизированы для детектирования пиков псевдомолекулярных и ассоциатных ионов. Для прямого ввода взяты растворы веществ в ацетонитриле (фирма «Merck», квалификация HPLC/MS) в концентрации до 1 мг/мл, скорость ввода не превышала 0,05 мкл/с. Результаты приведены в таблице 1.

Ихтиотоксичность проверяли на Poecilia reticulata (Poeciliidae) при температуре $23-25^{\circ} \mathrm{C}$. Методика эксперимента описана в [13]. Рыб (по 10 штук) помещали в 0,25·10 $0^{-3} \mathrm{M}$ растворы индивидуальных гликозидов, а также в их комплексы, содержащие по $0,25 \cdot 10^{-3} \mathrm{M}$ каждого из компонентов. Определяли время инкубации $t_{L D_{100}}$, в течение которого происходил $100 \%$ летальный исход (табл. 2). 
Таблица 1. Масс-спектры SC и его смесей с GC и гликозидами $\mathbf{1}$ и $\mathbf{2}$ (SC - цитрат силденафила, Sil - силденафил, GC - моноаммонийная соль глицирризиновой кислоты (глицирам), GA - глицирризиновая кислота, Cit - лимонная кислота)

\begin{tabular}{|c|c|c|}
\hline Ион & $m / z$ & $I_{\text {отн }}, \%$ \\
\hline \multicolumn{3}{|c|}{$S C$} \\
\hline$\left[\mathrm{M}^{\mathrm{Cit}}-\mathrm{H}\right]^{-}$ & 191,1 & 100 \\
\hline$\left[\mathrm{M}^{\mathrm{SC}}+\mathrm{Na}\right]^{+}$ & 689,6 & 2,4 \\
\hline$\left[\mathrm{M}^{\mathrm{Sil}}+\mathrm{Na}\right]^{+}$ & 497,5 & 1,2 \\
\hline$\left[\mathrm{M}^{\mathrm{Sil}}+\mathrm{H}\right]^{+}$ & 475,5 & 100 \\
\hline$\left[\mathrm{M}^{\mathrm{Cit}}+\mathrm{Na}\right]^{+}$ & 215,2 & 3,1 \\
\hline$\left[2 \mathrm{M}^{\mathrm{Sil}}+\mathrm{H}\right]^{+}$ & 949,9 & 8,8 \\
\hline \multicolumn{3}{|c|}{$G C$} \\
\hline$\left[\mathrm{M}^{\mathrm{GA}}-2 \mathrm{H}\right]^{2-}$ & 410,4 & 100 \\
\hline$\left[\mathrm{M}^{\mathbf{G A}}-\mathrm{H}\right]^{-}$ & 821,6 & 33,2 \\
\hline$\left[\mathrm{M}^{\mathbf{G A}}-3 \mathrm{H}\right]^{3-}$ & 273,3 & 1,8 \\
\hline$\left[3 \mathrm{M}^{\mathbf{G A}}-2 \mathrm{H}\right]^{2-}$ & 1232,9 & 1,6 \\
\hline$\left[\mathrm{M}^{\mathbf{G A}}+\mathrm{H}\right]^{+}$ & 823,8 & 100 \\
\hline$\left[3 \mathrm{M}^{\mathrm{GA}}+2 \mathrm{NH}_{4}\right]^{2+}$ & 1252,7 & 11,8 \\
\hline$\left[5 \mathrm{M}^{\mathrm{GA}}+3 \mathrm{NH}_{4}\right]^{3+}$ & 1390,0 & 1,2 \\
\hline$\left[2 \mathrm{M}^{\mathrm{GA}}+\mathrm{NH}_{4}\right]^{+}$ & 1664,5 & 1,8 \\
\hline \multicolumn{3}{|c|}{ Смесь SC и гликозида $\mathbf{I}$} \\
\hline$\left[\mathrm{M}^{\mathrm{Cit}}-\mathrm{H}\right]^{-}$ & 191,1 & 100 \\
\hline$\left[\mathrm{M}^{1}-\mathrm{H}\right]^{-}$ & 749,7 & 17,6 \\
\hline$\left[\mathrm{M}^{\mathrm{Sil}}-\mathrm{H}\right]^{-}$ & 473,4 & 4,4 \\
\hline$\left[2 \mathrm{M}^{1}-\mathrm{H}\right]^{-}$ & 1500,3 & 0,6 \\
\hline$\left[\mathrm{M}^{1}+\mathrm{M}^{\mathrm{Cit}}-\mathrm{H}\right]^{-}$ & 941,7 & 4,8 \\
\hline$\left[\mathrm{M}^{\mathrm{Sil}}+\mathrm{H}\right]^{+}$ & 475,5 & 100 \\
\hline$\left[\mathrm{M}^{\mathrm{Cit}}+\mathrm{K}\right]^{+}$ & 231,3 & 0,3 \\
\hline$\left[\mathrm{M}^{1}+\mathrm{Na}\right]^{+}$ & 773,8 & 0,8 \\
\hline$\left[\mathrm{M}^{\mathrm{SC}}+\mathrm{Na}\right]^{+}$ & 689,6 & 0,7 \\
\hline$\left[2 \mathrm{M}^{\mathrm{Sil}}+\mathrm{H}\right]^{+}$ & 949,9 & 2,6 \\
\hline$\left[\mathrm{M}^{1}+\mathrm{M}^{\mathrm{Sil}}+\mathrm{H}\right]^{+}$ & 1226,2 & 0,03 \\
\hline \multicolumn{3}{|c|}{ Смесь SC и гликозида 2} \\
\hline$\left[\mathrm{M}^{\mathrm{Cit}}-\mathrm{H}\right]^{-}$ & 191,1 & 100 \\
\hline$\left[\mathrm{M}^{\mathrm{Sil}}-\mathrm{H}\right]^{-}$ & 473,4 & 27,3 \\
\hline$\left[\mathrm{M}^{2}-\mathrm{H}\right]^{-}$ & 1219,9 & 3,2 \\
\hline$\left[\mathrm{M}^{\mathrm{Sil}}+\mathrm{H}\right]^{+}$ & 475,5 & 100 \\
\hline$\left[\mathrm{M}^{\mathrm{SC}}+\mathrm{Na}\right]^{+}$ & 689,6 & 0,6 \\
\hline$\left[2 \mathrm{M}^{\mathrm{Sil}}+\mathrm{H}\right]^{+}$ & 949,9 & 5,5 \\
\hline$\left[\mathrm{M}^{2}+\mathrm{Na}\right]^{+}$ & 1244,1 & 0,3 \\
\hline$\left[\mathrm{M}^{2}+\mathrm{M}^{\mathrm{Sil}}+\mathrm{H}\right]^{+}$ & 1696,5 & 0,01 \\
\hline \multicolumn{3}{|c|}{ Смесь $\boldsymbol{S C}$ и $\boldsymbol{G C}$} \\
\hline$\left[\mathrm{M}^{\mathrm{SiI}}-\mathrm{H}\right]^{-}$ & 473,4 & 2,7 \\
\hline$\left[\mathrm{M}^{\mathbf{G A}}-2 \mathrm{H}\right]^{2-}$ & 410,4 & 100 \\
\hline$\left[\mathrm{M}^{\mathrm{Cit}}-\mathrm{H}\right]^{-}$ & 191,1 & 1,0 \\
\hline$\left[\mathrm{M}^{\mathrm{GA}}+\mathrm{M}^{\mathrm{Cit}}-\mathrm{H}\right]^{-}$ & 1013,7 & 1,2 \\
\hline$\left[3 \mathrm{M}^{\mathbf{G A}}-2 \mathrm{H}\right]^{2-}$ & 1232,9 & 1,3 \\
\hline$\left[\mathrm{M}^{\mathrm{GA}}+\mathrm{M}^{\mathrm{Sil}}-\mathrm{H}\right]^{-}$ & 1295,9 & 0,8 \\
\hline$\left[\mathrm{M}^{\mathrm{SC}}+\mathrm{Na}\right]^{+}$ & 689,6 & 1,4 \\
\hline$\left[\mathrm{M}^{\mathrm{Sil}}+\mathrm{H}\right]^{+}$ & 475,5 & 100 \\
\hline$\left[\mathrm{M}^{\mathrm{Cit}}+\mathrm{Na}\right]^{+}$ & 215,2 & 26,3 \\
\hline$\left[\mathrm{M}^{\mathrm{GA}}+\mathrm{H}\right]^{+}$ & 823,8 & 1,0 \\
\hline
\end{tabular}

Таблица 2. Ихтиотоксичность SC, GC, гликозидов 1 и 2 и их комплексов против Poecilia reticulata

\begin{tabular}{c|c|c}
\hline Соединение & $c, \mathrm{M}$ & Время экспозиции $t_{L D_{100}}$ до летального исхода, мин \\
\hline SC & $0,25 \times 10^{-3}$ & $13,0 \pm 1,3$ \\
1 & $0,25 \times 10^{-3}$ & На протяжении 120 мин не токсично \\
2 & $0,25 \times 10^{-3}$ & На протяжении 120 мин не токсично \\
GC & $0,25 \times 10^{-3}$ & На протяжении 120 мин не токсично \\
Комплекс 1-SC & По $0,25 \times 10^{-3}$ каждого вещества & $21,4 \pm 0,2$ \\
Комплекс 2-SC & По $0,25 \times 10^{-3}$ каждого вещества & $42,4 \pm 1,5$ \\
Комплекс GC-SC & По $0,25 \times 10^{-3}$ каждого вещества & $41,4 \pm 7,3$ \\
\hline
\end{tabular}


Всхожесть семян Avena sativa L. (Роасеае) исследовали в лабораторных условиях при температуре $27-28{ }^{\circ} \mathrm{C}$ по методике, приведенной в $[8,14]$. Концентрации индивидуальных веществ, а также всех веществ в их комплексах составляли по $0,5 \cdot 10^{-4}$ М. Результаты приведены в таблице 3.

Таблица 3. Влияние $\mathbf{S C , ~ G C}$ и их комплекса на всхожесть семян Avena sativa L. в лабораторных условиях (концентрации индивидуальных веществ и веществ в комплексе по $0,5 \cdot 10^{-4} \mathrm{M}$ )

\begin{tabular}{|c|c|c|c|c|}
\hline \multirow{2}{*}{ Параметр } & \multicolumn{4}{|c|}{ Соединение } \\
\hline & $\mathrm{H}_{2} \mathrm{O}$ (контроль) & SC & GC & Комплекс GC c SC \\
\hline \multicolumn{5}{|c|}{ Через 24 ч после обработки } \\
\hline Всхожесть, \% & 52 & 56 & 28 & 60 \\
\hline Длина ростка, мм & $0,5 \pm 0,2$ & $0,6 \pm 0,2$ & $0,3 \pm 0,2$ & $0,9 \pm 0,4$ \\
\hline Количество с корнем, \% & 80 & 72 & 64 & 88 \\
\hline Длина корня, мм & $0,9 \pm 0,2$ & $1,0 \pm 0,3$ & $0,9 \pm 0,4$ & $2,1 \pm 0,7$ \\
\hline \multicolumn{5}{|c|}{ Через 48 ч после обработки } \\
\hline Всхожесть, \% & 76 & 84 & 72 & 80 \\
\hline Длина ростка, мм & $3,9 \pm 1,4$ & $2,2 \pm 0,9$ & $1,3 \pm 0,5$ & $2,0 \pm 0,7$ \\
\hline Количество с корнем, \% & 88 & 92 & 84 & 100 \\
\hline Длина корня, мм & $2,2 \pm 0,7$ & $3,5 \pm 1,4$ & $2,1 \pm 0,6$ & $3,8 \pm 1,0$ \\
\hline \multicolumn{5}{|c|}{ Через 72 ч после обработки } \\
\hline Всхожесть, \% & 92 & 88 & 84 & 80 \\
\hline Длина ростка, мм & $7,9 \pm 1,8$ & $5,9 \pm 2,1$ & $5,7 \pm 2,3$ & $4,2 \pm 1,4$ \\
\hline Количество с корнем, \% & 92 & 92 & 92 & 100 \\
\hline Длина корня, мм & $7,1 \pm 1,9$ & $6,4 \pm 2,4$ & $7,0 \pm 2,8$ & $5,9 \pm 1,7$ \\
\hline
\end{tabular}

\section{Обсуждение результатов}

Масс-спектрометрические данные. В масс-спектре индивидуального SC (табл. 1) наблюдали пики протонированного Sil и его димера. Кроме того, в спектре идентифицированы катионы SC, Sil и лимонной кислоты (Cit), содержащие $\mathrm{Na}^{+}$. В масс-спектре отрицательных ионов преобладает пик $\left[\mathrm{M}^{\mathrm{Cit}}-\mathrm{H}\right]^{-}$, относящийся к депротонированной Cit.

В масс-спектрах GC идентифицированы пики протонированной и депротонированной GA: $\left[\mathrm{M}^{\mathbf{G A}}+\mathrm{H}\right]^{+},\left[\mathrm{M}^{\mathbf{G A}}-\mathrm{H}\right]^{-},\left[\mathrm{M}^{\mathbf{G A}}-2 \mathrm{H}\right]^{2-}$ и $\left[\mathrm{M}^{\mathbf{G A}}-3 \mathrm{H}\right]^{3-}$. Известно, что GA склонна к самоассоциации $[1,2]$. Действительно, в масс-спектре индивидуального $\mathbf{G C}$ в режиме положительных ионов найдены пики катионизированных ассоциатов $\mathbf{G A}$, содержащих ионы $\mathrm{NH}_{4}^{+}:\left[2 \mathrm{M}^{\mathbf{G A}}+\mathrm{NH}_{4}\right]^{+},\left[3 \mathrm{M}^{\mathbf{G A}}+2 \mathrm{NH}_{4}\right]^{2+}$ и $\left[5 \mathrm{M}^{\mathbf{G A}}+3 \mathrm{NH}_{4}\right]^{3+}$. Интенсивности их сигналов соотносятся между собой как 1,5:9,8:1, соответственно. В спектре отрицательных ионов присутствует пик только одного депротонированного ассоциата $\left[3 \mathrm{M}^{\mathbf{G A}}-2 \mathrm{H}\right]^{2-}$. Таким образом, в массспектрах наблюдается явное преобладание пика тримера среди пиков других ассоциатов GA. Особенности масс-спектров индивидуальных гликозидов 1 и 2 были рассмотрены ранее [13].

Масс-спектр смеси гликозида 1 и $\mathbf{S C}$ имеет пик иона $\left[\mathrm{M}^{\mathbf{1}}+\mathrm{M}^{\mathrm{Sil}}+\mathrm{H}\right]^{+}$, отвечающий образованию комплекса состава 1:1. В масс-спектре отрицательных ионов регистрируется пик иона комплекса гликозида 1 и Cit $\left[\mathrm{M}^{1}+\mathrm{M}^{\mathrm{Cit}}-\mathrm{H}\right]^{-}$, также имеющий эквимолярный состав. Для комплекса гликозида 2 в масс-спектре положительных ионов зафиксирован малоинтенсивный пик $\left[\mathrm{M}^{2}+\mathrm{M}^{\mathrm{Sil}}+\mathrm{H}\right]^{+}$. Формирование комплексов гликозидов 1 и 2 с более сложным составом не установлено. Таким образом, гликозиды плюща образуют с GA только комплексы состава $1: 1$. Относительная интенсивность пика иона комплекса $\left[\mathrm{M}^{1}+\mathrm{M}^{\mathrm{Sil}}+\mathrm{H}\right]^{+}$в 3 раза больше интенсивности пика иона $\left[\mathrm{M}^{2}+\mathrm{M}^{\mathrm{Sil}}+\mathrm{H}\right]^{+}$. Возможно, что первый комплекс несколько более устойчив из-за наличия свободной карбоксильной группы в молекуле гликозида 1, которая может протонировать атом азота метилпиперазинового кольца Sil. В отличие от гликозида 1, гликозид 2 не содержит карбоксильной группы, поэтому он может взаимодействовать с Sil посредством своих многочисленных гидроксильных групп углеводных частей и неполярной агликонной части.

В масс-спектре смеси $\mathbf{G C}$ и $\mathbf{S C}$ обнаружен пик иона $\left[\mathrm{M}^{\mathbf{G A}}+\mathrm{M}^{\mathrm{Sil}}-\mathrm{H}\right]^{-}$, указывающий на образование молекулярного комплекса состава $1: 1$. Несмотря на то, что в масс-спектрах индивидуального GC и его смеси с SC зафиксированы пики ионов ди-, три- и пентамеров GA, комплексы с их участием не образуются. Ранее методом изомолярных серий было показано, что в водных растворах SC образует с GC и гликозидами 1 и 2 молекулярные комплексы состава 1:1 [7, 8]. В молекуле GA три карбоксильных группы, поэтому она, как и гликозид 1, может протонировать молекулу Sil. 
Ихтиотоксичность. Характерной особенностью тритерпеновых гликозидов является ихтиотоксичность [15]. Нами установлено, что гликозид $\mathbf{2}, \mathbf{S C}$ и GC не вызвали гибель рыб гуппи P. reticulata в течение 120 мин, а монодесмозидный гликозид 1 оказался токсичным (табл. 2). Это объясняется наличием свободной карбоксильной группы у атома С-17 его агликона. В агликонной части GC имеется свободная карбоксильная группа, но она расположена у атома С-20.

Комплекс гликозида 1 с SC является наиболее ихтиотоксичным среди рассмотренных комплексов. Для него время инкубации $t_{L D_{100}}$ в среднем в 2 раза меньше, чем у остальных комплексов. Комплексы 2SC и GC-SC обладают близкой активностью.

Все комплексы оказались более токсичными по сравнению с индивидуальным SC. Комплекс гликозида $\mathbf{1}$ с SC проявил меньшую токсичность, чем индивидуальный гликозид 1. Однако комплексы гликозида 2 и GC c SC, наоборот, были более активны, чем исходные гликозиды.

Аллелопатическая активность. Сапонины обладают аллелопатической активностью [16, 17]. Ранее сообщалось, что SC также способен влиять на развитие растений [18]. Аллелопатическая активность комплексов гликозидов плюща $\mathbf{1}$ и $\mathbf{2}$ с SC описана в [8]. Нами рассмотрено действие $\mathbf{S C}, \mathbf{G C}$, а также их комплексов на всхожесть семян овса посевного Avena sativa L. (табл. 3).

GA, как и фитотоксичный гликозид 1, имеет монодесмозидную природу. Однако ее соль GC через 72 ч после обработки вызывает всхожесть, равную 84\%, что практически совпадает со всхожестью семян в группе, обработанной раствором бисдесмозидного гликозида 2 (86\%). В агликонной части гликозида 1 свободная карбоксильная группа расположена у атома С-17, а у GC - у C-20. Очевидно, что данное структурное отличие отражается на степени как ихтио-, так и фитотоксической активности веществ.

Через 72 ч всхожесть у семян, обработанных комплексом GC-SC, составила 80\%. Это несколько меньше, чем у семян в контрольной группе (92\%) и после обработки растворами индивидуальных GC $(84 \%)$ и SC (88\%). Ранее было показано, что комплекс гликозида 2 с SC не подавлял всхожесть семян при тех же самых условиях эксперимента [8]. Всхожесть семян в этом случае составила 92\%, т.е. совпала со всхожестью в контрольной группе. Комплекс гликозида 1, как и комплекс GC c SC, несколько тормозит прорастание семян. Всхожесть семян после обработки этим комплексом равна 76\% [8].

Комплекс GC c SC благотворно влияет на появление корневой системы у проростков. Через 72 ч после вымачивания семян в комплексе GC c SC их количество с корнем оказалось 100\%, хотя в контрольной группе и для индивидуальных компонентов комплекса оно оказалось одинаковым и составило только $92 \%$. По сравнению с комплексом GC-SC комплексы гликозидов плюща не способствовали повышению количества семян с корнем. Количество семян с корнем после обработки комплексами гликозидов 1 и 2 с SC составило только 84 и $92 \%$, соответственно [8].

\section{Bblводbl}

1. Методом масс-спектрометрии установлено, что гликозиды плюща и солодки образуют с Sil межмолекулярные комплексы состава $1: 1$.

2. Комплекс гликозида $\mathbf{1}$ с SC является наиболее ихтиотоксичным среди изученных комплексов. Все комплексы оказались более токсичными по сравнению с индивидуальным SC.

3. Комплекс GC c SC незначительно подавляет всхожесть семян, но способствует появлению корней у проростков.

\section{Список литературы}

1. Толстикова Т.Г., Толстиков А.Г., Толстиков Г.А. На пути к низкодозным лекарствам // Вестник РАН. 2007. T. 77, №10. C. 867-874.

2. Толстиков Г.А., Балтина Л.А., Гранкина В.П., Кондратенко Р.М., Толстикова Т.Г. Солодка: Биоразнообразие, химия, применение в медицине. Новосибирск, 2007. 311 с.

3. Tolstikova T.G., Khvostov M.V., Bryzgalov A.O. The complexes of drugs with carbohydrate-containing plant metabolites as pharmacologically promising agents // Mini-Reviews in Medicinal Chemistry. 2009. Vol. 9. Pp. 1317-1328.

4. Далимов Д.Н., Исаев Ю.Т., Сайиткулов А.М. Молекулярные комплексы моноаммониевой соли глицирризиновой кислоты с некоторыми лекарственными средствами и их интерферониндуцирующая активность // Химия природных соединений. 2001. №2. С. 132-134. 
5. Hu Y.-J., Liu Y., Wang J.-B., Xiao X.-H., Qu S.-S. Study of the interaction between monoammonium glycyrrhizinate and bovine serum albumin // Journal of Pharmaceutical and Biomedical Analysis. 2004. Vol. 36. Pp. 915-919.

6. Yakovishin L.A., Grishkovets V.I., Schroeder G., Borisenko N.I. Molecular complexation of ivy saponins with some drugs and biologically active substances // Functionalized molecules - synthesis, properties and application / ed. V.I. Rybachenko. Donetsk, 2010. Ch. 4. Pp. 85-103.

7. Yakovishin L.A., Grishkovets V.I., Belash D.Yu., Yarovoy I.R. Molecular complexation of ivy and licorice saponins with some drugs of aromatic nature // Ученые записки Таврического национального университета им. В.И. Вернадского. Сер. Биология, химия. 2011. Т. 24, №3. С. 4-10.

8. Яковишин Л.А., Гришковец В.И., Белаш Д.Ю., Яровой И.Р. Супрамолекулярные комплексы тритерпеновых гликозидов с цитратом силденафила: образование в водно-спиртовых растворах и биологическая активность // Ученые записки Таврического национального университета им. В.И. Вернадского. Сер. Биология, химия. 2011. T. 24, №2. C. 408-414.

9. Drewes S.E., George J., Khan F. Recent findings on natural products with erectile-dysfunction activity // Phytochemistry. 2003. Vol. 62. Pp. 1019-1025.

10. Колотилова О.И., Яковишин Л.А., Коренюк И.И., Гришковец В.И, Хусаинов Д.Р., Гамма Т.В. Влияние виагры и ее комплексов с тритерпеновыми гликозидами на электрическую активность нейронов моллюска Helix albescens // Ученые записки Таврического национального университета им. В.И. Вернадского. Сер. Биология, химия. 2010. Т. 23, №2. С. 96-103.

11. Шашков А.С., Гришковец В.И., Лолойко А.А., Чирва В.Я. Тритерпеновые гликозиды Hedera taurica I. Строение таурозида Е из листьев Hedera taurica // Химия природных соединений. 1987. №3. С. 363-366.

12. Гришковец В.И., Сидоров Д.Ю., Яковишин Л.А., Арнаутов Н.Н., Шашков А.С., Чирва В.Я. Тритерпеновые гликозиды Hedera canariensis I. Строение гликозидов L-A, L-B, L-B $_{2}, \mathrm{~L}-\mathrm{C}, \mathrm{L}-\mathrm{D}, \mathrm{L}-\mathrm{E}_{1}, \mathrm{~L}_{-} \mathrm{G}_{1}, \mathrm{~L}_{-} \mathrm{G}_{2}, \mathrm{~L}_{-} \mathrm{G}_{3}, \mathrm{~L}_{4} \mathrm{G}_{4}$, L-H ${ }_{1}, \mathrm{~L}_{2} \mathrm{H}_{2}$ и L-I $\mathrm{I}_{1}$ из листьев Hedera canariensis // Химия природных соединений. 1996. №3. С. 377-383.

13. Яковишин Л.А., Борисенко Н.И., Руднев М.И., Ветрова Е.В., Гришковец В.И. Самоассоциация и комплексообразование тритерпеновых гликозидов и холестерина // Химия природных соединений. 2010. № 1. С. $45-48$.

14. Яковишин Л.А., Лекарь А.В., Борисенко С.Н., Ветрова Е.В., Борисенко Н.И., Гришковец В.И. Молекулярное комплексообразование сапонинов плюща с $L$-триптофаном // Химия растительного сырья. 2011. №4. С. 65-70.

15. Hostettmann K., Marston A. Saponins. Cambridge, 1995. 548 p.

16. Oleszek W., Jurzysta M. The allelopathic potential of alfalfa root medicagenic acid glycosides and their fate in soil environments // Plant and Soil. 1987. Vol. 98. Pp 67-80.

17. Wyman-Simpson C.L., Waller G.R., Jurzysta M., McPherson J.K., Young C.C. Biological activity and chemical isolation of root saponins of six cultivars of alfalfa (Medicago sativa L.) // Plant and Soil. 1991. Vol. 135. Pp 83-94.

18. Vaidyanathan P., Francis K. Impact of sildenafil citrate on tissue culture of tobacco (Nicotiana tabaccum) // Plant Cell Biotechnology and Molecular Biology. 2009. Vol. 10, N1/2. Pp. 49-56.

Поступило в редакичию 25 сентября 2012 г. 
Yakovishin L.A. ${ }^{{ }^{*},}$, Lekar A.V. ${ }^{2}$, Vetrova E.V. ${ }^{2}$, Borisenko N.I. ${ }^{3}$, Borisenko S.N. ${ }^{2}$, Grishkovets V.I. ${ }^{4}$ MOLECULAR COMPLEXES OF IVY AND LICORICE SAPONINS WITH SILDENAFIL CITRATE (VIAGRA) AND ITS BIOLOGICAL ACTIVITY

${ }^{\text {I}}$ Sevastopol National Technical University, Universitetskaya Str., 33, Sevastopol, 99053 (Ukraine), e-mail: chemsevntu@rambler.ru

${ }^{2}$ Institute of Physical and Organic Chemistry, Southern Federal University, Stachka Ave., 194/2, Rostov-on-Don, 344090 (Russia)

${ }^{3}$ Ecological and Analytical Center, Southern Federal University, Zorge Str., 7, Rostov-on-Don, 344090 (Russia)

${ }^{4}$ V.I. Vernadsky Taurida National University, Vernadsky Ave., 4, Simferopol, 95007 (Ukraine)

The molecular complexation of triterpene glycosides $\alpha$-hederin (hederagenin 3-O- $\alpha$ - $L$-rhamnopyranosyl-(1 $\rightarrow 2)-O-\alpha-L-$ arabinopyranoside), hederasaponin $\mathrm{C}$ (hederagenin 3-O- $\alpha-L$-rhamnopyranosyl-( $1 \rightarrow 2)-O$ - $\alpha$ - $L$-arabinopyranosyl-28- $O-\alpha-L$ rhamnopyranosyl- $(1 \rightarrow 4)-O-\beta$ - $D$-glucopyranosyl- $(1 \rightarrow 6)-O-\beta-D$-glucopyranoside) and glycyram (monoammonium glycyrrhizinate) with sildenafil citrate was investigated for the first time using the electrospray ionization mass spectroscopy. The glycosides form complex in the 1:1 molar ratio. The influence of complex on Avena sativa seeds germination and its ichthyotoxicity against Poecilia reticulata were studied.

Keywords: triterpene glycosides, $\alpha$-hederin, hederasaponin C, glycyram, sildenafil citrate, molecular complex, mass spectroscopy, ichthyotoxicity, allelopathic activity.

\section{References}

1. Tolstikova T.G., Tolstikov A.G., Tolstikov G.A. Vestnik RAN, 2007, vol. 77, no. 10, pp. 867-874. (in Russ.).

2. Tolstikov G.A., Baltina L.A., Grankina V.P., Kondratenko R.M., Tolstikova T.G. Solodka: Bioraznoobrazie, khimiia, primenenie v meditsine. [Licorice: biodiversity, chemistry, medical applications.]. Novosibirsk, 2007, 311 p. (in Russ.).

3. Tolstikova T.G., Khvostov M.V., Bryzgalov A.O. Mini-Reviews in Medicinal Chemistry, 2009, vol. 9, pp. 1317-1328.

4. Dalimov D.N., Isaev Iu.T., Saiitkulov A.M. Khimiia prirodnykh soedinenii, 2001, no. 2, pp. 132-134. (in Russ.).

5. Hu Y.-J., Liu Y., Wang J.-B., Xiao X.-H., Qu S.-S. Journal of Pharmaceutical and Biomedical Analysis, 2004, vol. 36, pp. 915-919.

6. Yakovishin L.A., Grishkovets V.I., Schroeder G., Borisenko N.I. Functionalized molecules - synthesis, properties and application / ed. V.I. Rybachenko. Donetsk, 2010. Ch. 4. Pp. 85-103.

7. Yakovishin L.A., Grishkovets V.I., Belash D.Yu., Yarovoy I.R. Uchenye zapiski Tavricheskogo natsional'nogo universiteta im. V.I. Vernadskogo. Ser. Biologiia, khimiia, 2011, vol. 24, no. 3, pp. 4-10. (in Engl.).

8. Yakovishin L.A., Grishkovets V.I., Belash D.Yu., Yarovoy I.R. Uchenye zapiski Tavricheskogo natsional'nogo universiteta im. V.I. Vernadskogo. Ser. Biologiia, khimiia, 2011, vol. 24, no. 2, pp. 408-414. (in Russ.).

9. Drewes S.E., George J., Khan F. Phytochemistry, 2003, vol. 62, pp. 1019-1025.

10. Kolotilova O.I., Iakovishin L.A., Koreniuk I.I., Grishkovets V.I, Khusainov D.R., Gamma T.V. Uchenye zapiski Tavricheskogo natsional'nogo universiteta im. V.I. Vernadskogo. Ser. Biologiia, khimiia, 2010, vol. 23, no. 2, pp. $96-$ 103. (in Russ.).

11. Shashkov A.S., Grishkovets V.I., Loloiko A.A., Chirva V.Ia. Khimiia prirodnykh soedinenii, 1987, no. 3, pp. 363366. (in Russ.).

12. Grishkovets V.I., Sidorov D.Iu., Iakovishin L.A., Arnautov N.N., Shashkov A.S., Chirva V.Ia. Khimiia prirodnykh soedinenii, 1996, no. 3, pp. 377-383. (in Russ.).

13. Iakovishin L.A., Borisenko N.I., Rudnev M.I., Vetrova E.V., Grishkovets V.I. Khimiia prirodnykh soedinenii, 2010, no. 1, pp. 45-48. (in Russ.).

14. Iakovishin L.A., Lekar' A.V., Borisenko S.N., Vetrova E.V., Borisenko N.I., Grishkovets V.I. Khimiia rastitel'nogo syr'ia, 2011, no. 4, pp. 65-70. (in Russ.).

15. Hostettmann K., Marston A. Saponins. Cambridge, 1995. 548 p.

16. Oleszek W., Jurzysta M. Plant and Soil., 1987, vol. 98, pp 67-80.

17. Wyman-Simpson C.L., Waller G.R., Jurzysta M., McPherson J.K., Young C.C. Plant and Soil., 1991., vol. 135, pp. 83-94.

18. Vaidyanathan P., Francis K. Plant Cell Biotechnology and Molecular Biology, 2009, vol. 10, no. 1/2, pp. 49-56.

Received September 25, 2012

\footnotetext{
* Corresponding author.
} 
